\title{
The surgical treatment of metastatic spine tumors within the intramedullary compartment
}

\author{
Ben A. Strickland, MD, lan E. McCutcheon, MD, FRCS(C), Indro Chakrabarti, MD, MPH, \\ Laurence D. Rhines, MD, and Jeffrey S. Weinberg, MD \\ Department of Neurosurgery, The University of Texas MD Anderson Cancer Center, Houston, Texas
}

\begin{abstract}
OBJECTIVE Metastasis to the spinal cord is rare, and optimal management of this disease is unclear. The authors investigated this issue by analyzing the results of surgical treatment of spinal intramedullary metastasis (IM) at a major cancer center.

METHODS The authors retrospectively reviewed the medical records of 13 patients who underwent surgery for IM. Patients had renal cell carcinoma $(n=4)$, breast carcinoma $(n=3)$, melanoma $(n=2)$, non-small cell lung cancer $(n=1)$, sarcoma $(n=1)$, adenoid cystic carcinoma $(n=1)$, and cervical cancer $(n=1)$. Cerebrospinal fluid was collected before surgery in 11 patients, and was negative for malignant cells, as was MRI of the neuraxis. Eleven patients presented with neurological function equivalent to Frankel Grade D.
\end{abstract}

RESULTS Radiographic gross-total resection was achieved in 9 patients, and tumor eventually recurred locally in 3 of those $9(33 \%)$. Leptomeningeal disease was diagnosed in 4 patients after surgery. In the immediate postoperative period, neurological function in 6 patients deteriorated to Frankel Grade C. At 2 months, only 2 patients remained at Grade C, 8 were at Grade D, and 1 had improved to Grade E. One patient developed postoperative hematoma resulting in Frankel Grade A. Radiotherapy was delivered in 8 patients postoperatively. The median survival after spine surgery was 6.5 months. Three patients are still living.

CONCLUSIONS Surgery was performed as a last option to preserve neurological function in patients with IM. In most patients, neurological function returned during the immediate postoperative period and was preserved for the patients' remaining lifetime. The data suggest that surgery can be effective in preventing further decline in selected patients with progressive neurological deficit.

https://thejns.org/doi/abs/10.3171/2017.5.SPINE161161

KEY WORDS intramedullary metastasis; spine surgery; oncology; surgical technique

$\mathrm{R}$ ESECTION is often a late treatment option for patients with spinal intramedullary metastasis (IM), and is often excluded due to worry over a perceived high risk/benefit ratio. Development of guidelines for treating these patients, which has been hindered by the disproportionate rarity of IMs relative to brain metastases, must consider histological findings, life expectancy, and maintenance of neurological function. The incidence of IM in autopsy series of patients with cancer ranges from $0.9 \%$ to $3.5 \% .^{4,6,16}$ One author found IM in $2 \%$ of patients with end-stage cancer, and another showed that $6 \%$ of patients with cancer who had myelopathy had one or more IMs. ${ }^{6,27}$ With survival increasing among cancer patients due to improved therapies, IM will probably be seen more frequently. When left untreated, neurological decline usually follows, with progression to paraparesis or quadriparesis. ${ }^{13}$ Although advances in radiographic imaging now enable the detection of tumors at an earlier stage, even in recent series treatment often consists of steroids and radiotherapy. ${ }^{19,21,26}$ Here we outline the clinical parameters and outcomes of patients with IM treated surgically at our institution.

\section{Methods}

We queried institutional databases as well as the data-

ABBREVIATIONS GTR = gross-total resection; IM = intramedullary metastasis; KPS = Karnofsky Performance Scale; $L M D$ = leptomeningeal disease; SRS = stereotactic radiosurgery; STR = subtotal resection; WBRT = whole-brain radiotherapy.

SUBMITTED October 2, 2016. ACCEPTED May 22, 2017.

INCLUDE WHEN CITING Published online November 10, 2017; DOI: 10.3171/2017.5.SPINE161161. 
TABLE 1. Intramedullary spinal cord metastasis: clinical profile

\begin{tabular}{|c|c|c|c|c|c|c|c|c|c|c|c|}
\hline $\begin{array}{l}\text { Case } \\
\text { No. }\end{array}$ & Pathology & $\begin{array}{l}\text { Age/ } \\
\text { Sex }\end{array}$ & $\begin{array}{c}\text { Time } \\
\text { From } \\
\text { Cancer } \\
\text { Dx to Sx } \\
\text { (mos) }\end{array}$ & $\begin{array}{l}\text { KPS } \\
\text { Score }\end{array}$ & $\begin{array}{c}\text { Medical } \\
\text { Comorbidities }\end{array}$ & $\begin{array}{c}\text { Active Systemic } \\
\text { Disease Sites }\end{array}$ & Location & $\begin{array}{c}\begin{array}{c}\text { Extent } \\
\text { of } \\
\text { Resection }\end{array}\end{array}$ & $\begin{array}{c}\text { Postop } \\
\text { Complications }\end{array}$ & $\begin{array}{c}\text { Inpatient } \\
\text { Rehabilitation }\end{array}$ & Disposition \\
\hline 1 & $\begin{array}{l}\text { Lung (large } \\
\text { cell) }\end{array}$ & $48 / \mathrm{M}$ & 17 & 90 & $\begin{array}{l}\text { Malignant } \\
\text { pleural } \\
\text { effusion }\end{array}$ & None & C-1 & GTR & $\begin{array}{l}\text { Pneumonia } \\
\text { tracheos- } \\
\text { tomy }\end{array}$ & No & $\begin{array}{c}\text { Subacute } \\
\text { nursing } \\
\text { facility }\end{array}$ \\
\hline 2 & Cervix & $37 / F$ & 32 & 90 & None & $\begin{array}{l}\text { Brain s/p WBRT, } \\
\text { liver, femur }\end{array}$ & T-6 & STR & None & Yes & Home \\
\hline 3 & Melanoma & $43 / \mathrm{M}$ & 34 & 90 & None & None & C-5 & GTR & CSF leak & No & Home \\
\hline 4 & Renal & $50 / \mathrm{M}$ & 64 & 90 & Hypertension & None & C-1 & GTR & None & Yes & Home \\
\hline 5 & Breast & $53 / F$ & 32 & 90 & None & None & C-2 & GTR & None & Yes & Home \\
\hline 6 & Breast & $48 / F$ & 133 & 100 & None & $\begin{array}{l}\text { Brain s/p WBRT } \\
\text { SRS }\end{array}$ & T-3 & GTR & None & Yes & Home \\
\hline 7 & Renal & $50 / \mathrm{M}$ & 92 & 80 & None & Brain & $C-5$ & GTR & DVT & Yes & $\begin{array}{l}\text { Skilled nurs- } \\
\text { ing facility }\end{array}$ \\
\hline 8 & Breast & $50 / F$ & 17 & 80 & None & Brain, rib & $\mathrm{T}-11$ & STR & None & Yes & Home \\
\hline 9 & $\begin{array}{l}\text { Adenoid cys- } \\
\text { tic breast } \\
\text { cancer }\end{array}$ & $70 / F$ & 120 & 90 & None & Brain, lung & C7-T2 & GTR & $\begin{array}{l}\text { Hematoma, } \\
\text { paraplegia }\end{array}$ & Yes & Home \\
\hline 10 & Sarcoma & $65 / \mathrm{M}$ & 2 & 80 & None & Skull & T-2 & STR & None & Yes & Home \\
\hline 11 & Melanoma & $56 / \mathrm{M}$ & Unknown & 80 & None & None & C-1 & STR & CSF leak & Yes & Home \\
\hline \multirow[t]{2}{*}{12} & \multirow[t]{2}{*}{ Renal } & $66 / M$ & 97 & 90 & \multirow{2}{*}{$\begin{array}{l}\text { Atrial fibrilla- } \\
\text { tion }\end{array}$} & \multirow[t]{2}{*}{ Femur } & $\mathrm{T}-11$ & GTR & None & Yes & Home \\
\hline & & $68 / \mathrm{M}$ & 110 & 80 & & & $\mathrm{~T}-11$ & GTR & None & Yes & Home \\
\hline 13 & Renal & $59 / \mathrm{M}$ & 32 & 90 & None & Brain & C-3 & GTR & None & Yes & Home \\
\hline
\end{tabular}

DVT = deep venous thrombosis; $\mathrm{Dx}=$ diagnosis; $\mathrm{s} / \mathrm{p}=$ status post; $\mathrm{Sx}=$ symptoms.

base of the Department of Neurosurgery at the MD Anderson Cancer Center for patients with IM who underwent resection $(n=13)$ between June 1, 1993, and November 30, 2014. These cases represent $0.35 \%$ of all spine operations and $4 \%$ of all intradural spinal procedures performed during the period. Patients with known leptomeningeal disease (LMD) or multiple intramedullary tumors were excluded, as was 1 patient with primary intramedullary melanoma that was classified as such due to the absence of any sites of melanoma outside the CNS. The institutional review board approved this study.

We recorded the following clinical and radiographic data for each patient: date of primary cancer diagnosis; date of spinal metastasis diagnosis; date of surgery; preoperative and postoperative radiotherapy received; surgical procedure; tumor characteristics; preoperative and postoperative neurological function, including Karnofsky Performance Scale (KPS) score and Frankel scores for spinal cord function recorded at various intervals; local recurrence; complications after surgery; and survival. ${ }^{11}$ Follow-up was recorded through September 1, 2016, for each patient.

Radiographic investigations in the preoperative period included plain radiographs, CT scans, and MRI. Subsequent surveillance was performed with MRI. The degree of resection was confirmed in all patients by postoperative imaging. Follow-up MRIs were assessed bimonthly for disease recurrence. Pain was assessed with a visual analog pain scale score ranging from 1 to 10 .

Resection in all patients was done by laminectomy, intradural exploration, and cord entry guided by intraoperative ultrasonography. Neurophysiological monitoring of cord function (motor and somatosensory evoked potentials) was performed in all patients.

\section{Results}

\section{Clinical Data Summary}

Table 1 shows clinical data for individual patients, and Table 2 summarizes the clinical findings for the entire cohort. The study cohort $(n=13)$ comprised 5 women and 8 men. No patient had epidural spinal metastasis or IM at another site. In 11 patients, CSF was tested before spine surgery (or prior to dural opening during the operation) and was negative for malignant cells in each case. In the remaining 2 patients CSF was not analyzed, but neither individual had radiographic evidence of LMD on MRI sequences of the neuraxis, nor did they develop LMD after surgery.

Eight patients had a history of disease at other sites: prior metastasis had occurred in the brain $(n=6)$, lung $(\mathrm{n}=1)$, and liver $(\mathrm{n}=1)$. All achieved control of systemic tumor, either surgically or with chemotherapy and radiotherapy, before surgery for the IM. In addition, the patient 
TABLE 2. Intramedullary spinal cord metastasis: clinical data summary

\begin{tabular}{ll}
\hline \multicolumn{1}{c}{ Variable } & \multicolumn{1}{c}{ Value } \\
\hline Median age at spine surgery, in yrs & 50 (range 37-70) \\
\hline $\begin{array}{l}\text { Median time from primary to spinal cord } \\
\text { metastasis, in mos }\end{array}$ & 33 (range 2-133) \\
\hline Median preop KPS score & 90 \\
\hline Median preop Frankel grade & $\mathrm{D}$ \\
\hline Preop CSF cytology & $\begin{array}{c}\text { Available for 11 of 13 } \\
\text { patients, all negative } \\
\text { for malignant cells }\end{array}$ \\
\hline Median length of hospital stay, in days & 17 (range 7-57) \\
\hline Median survival after surgery, in mos & 6.5 (range 2.2-65) \\
\hline
\end{tabular}

in Case 8 with breast carcinoma had an untreated rib metastasis, and the one in Case 2 with carcinoma of the cervix had untreated disease in the liver and femur. The patient in Case 12 had known oligometastatic disease to several sites in the bone.

At the time of surgery for IM, 7 patients had prior or present disease in the brain. The patient in Case 2 had widely metastatic cervical cancer with numerous small brain metastases, and had metastasis to the femur and liver. She was treated with whole-brain radiotherapy (WBRT), and her systemic disease was controlled at the time of IM surgery. In Case 6, the patient had undergone craniotomy and WBRT for a solitary cerebellar metastasis 1 year before resection of the IM. A small recurrence of the cerebellar lesion diagnosed 5 months before IM resection was treated with stereotactic radiosurgery (SRS). This disease was stable at the time of IM surgery. The patient in Case 7, who had been treated elsewhere for renal cell carcinoma, subsequently presented to our institution with symptoms of IM, at which time a small frontal lobe metastasis was also diagnosed (and later treated with SRS). The patient in Case 8 was found to have synchronous brain metastasis, which was treated with WBRT. In Case 9 the patient underwent resection and SRS 10 years prior to IM for adenoid cystic carcinoma of the hard palate; wedge resection of a lung metastasis 3 years prior to IM; craniotomy for removal of a previously irradiated cerebellar metastasis 2 years prior to IM; and a second craniotomy for removal of an occipital tumor (also previously irradiated) 7 months prior to IM surgery. There was no evidence of cranial disease at the time of IM surgery. The patient in Case 10 had a parotid adenocarcinoma resected and treated with radiotherapy 20 years prior to IM. Two months prior to IM he was diagnosed with radiation-induced sarcoma of the temporal bone, which was resected, then treated with chemotherapy due to disease recurrence. He was found to have cranial involvement by direct extension at the time of IM surgery. Finally, the patient in Case 13 had undergone craniotomy for a cranial lesion 32 months prior to IM surgery. There was no evidence of cranial disease at the time of IM surgery.

\section{Treatment Modalities}

All patients had been treated with systemic chemo- therapy for their known primary disease. The IM in each patient was treated with laminectomy, intradural exploration, and microsurgical removal of the intramedullary tumor (Table 1). Cord entry was guided by intraoperative ultrasonography. Resection was achieved by internal debulking of the tumor, followed by separation of the marginal remnants from the adjacent cord parenchyma. En bloc removal was not done, to minimize the risk of cord injury. We were careful to avoid gross spillage of tumor fragments into the surrounding subarachnoid space, and placed cottonoids in that space above and below the operative site to aid that goal. Microscopic spillage could not, however, be excluded. Intraoperative ultrasonography was used to plan the myelotomy and to judge the extent of resection. Somatosensory and motor evoked potentials were monitored during surgery in all patients. In all patients a transient decline in wave amplitudes occurred during dissection, but waveforms always returned to baseline by the time of completion of tumor resection. Nine patients had gross-total resection (GTR), and 4 had subtotal resection (STR), as verified by postoperative MRI (Fig. 1).

In 4 patients (Cases 1, 4, 6, and 13) the IM was treated with surgery but not adjuvant radiotherapy. The patient in Case 13 had 2 operations, with radiotherapy given only after the second (not shown), which was done to resect local recurrence at the operative site. In addition, 1 patient (Case 5) had already received radiotherapy for IM. Her neurological function improved substantially thereafter, and the tumor size initially was stable on imaging. However, she was steroid dependent, and 5 months later her neurological function deteriorated and MRI demonstrated tumor growth. She then underwent a microsurgical GTR, and completed a slow wean from steroids.

Eight other patients were treated with postoperative radiotherapy. In Case 2, the patient (with cervical carcinoma) had STR and then radiotherapy to the spinal site. Two months after surgery, this patient was diagnosed with LMD and an Ommaya reservoir was placed for intrathecal administration of chemotherapy. The patient in Case 3 (with melanoma) received the same radiotherapy regimen. This patient had undergone GTR, and radiotherapy was given to prevent local recurrence. Three months after IM surgery, brain metastasis was discovered and treated with WBRT. The patient in Case 7 (with renal cell carcinoma) was treated with GTR and received postoperative radiotherapy after local recurrence of IM was discovered. In Case 8, the patient had STR, and then irradiation at the operative site followed by WBRT for synchronous metastasis. The patient in Case 9 (with adenoid cystic carcinoma) was treated with GTR but developed an epidural hematoma and sudden paraplegia 1 week after surgery. After hematoma evacuation she received radiotherapy, and is alive 21 months later without evidence of recurrence. The patient in Case 10 (with radiation-induced sarcoma) underwent an STR and adjuvant radiotherapy but died 4 months later of unknown causes. In Case 11 (patient with melanoma) the individual underwent STR followed by radiotherapy, and died of hepatic failure at 36 months. The patient in Case 12 (with renal cell carcinoma) underwent GTR without postoperative radiotherapy. This patient was found to have local recurrence 1 year after treatment and 

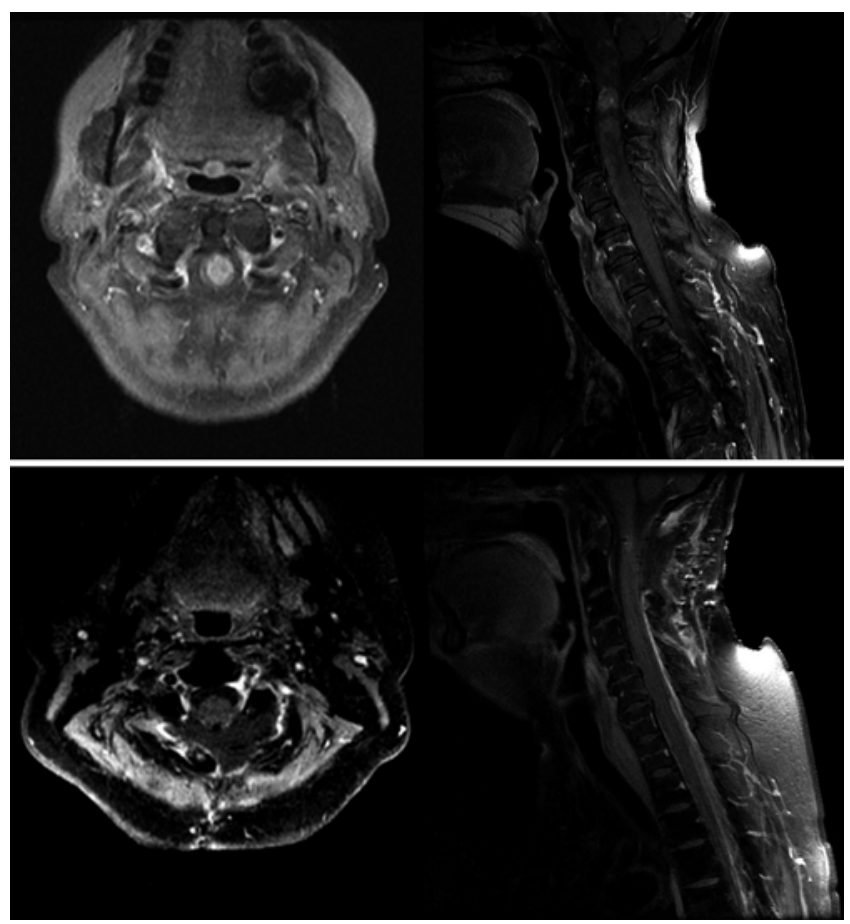

FIG. 1. Unifying features of IM include tumor location, presence of significant cord edema, absence of tumor-associated cyst or syrinx, and the occasional presence of LMD. Inhomogeneous or ring enhancement (suggesting central necrosis associated with rapid growth) is often noted (see Dam-Hieu et al.). All patients included in our series fit this radiographic profile, a typical example of which is the patient in Case 5. Upper: Preoperative axial and sagittal, postcontrast MRI showing an intramedullary breast cancer metastasis. The lesion, located eccentrically to the left but contained within the spinal cord, has a large enhancing focus with surrounding rostral and caudal edema in the spinal cord. Lower: Axial and sagittal postcontrast MRI obtained 24 hours after surgery showing GTR of the lesion and reexpansion of spinal cord, with minimal residual enhancement.

underwent a second resection and course of radiotherapy (35 Gy in 14 fractions), and remains alive at 65 months. He remained ambulatory for 51 months after IM surgery, at which point he required amputation of a leg for intractable pathological fractures.

\section{Surgical Findings}

In all cases, the tumors had a color distinct from that of the surrounding cord. In 8 patients, the cord was observed to have expanded on radiographic studies and on direct inspection during surgery. Tumor location was independent of histological findings, and was dorsal and eccentric in 4 patients, dorsal and midline in 7 patients, and central (i.e., contained completely within the cord parenchyma, with no contact with the pial surface) in 2 patients. One patient's tumor was both intraparenchymal and slightly exophytic; all other tumors were confined within the cord. The tumors had a discernible cleavage plane in 6 patients. In 3 patients a cleavage plane was evident, but the tumor was more adherent to cord tissue. Finally, in the patients in Cases 2, 8, 10, and 11, the absence of a distinct plane between tumor and neural tissue led to STR.

\section{Postoperative Complications}

Three surgical site-related complications (CSF leak in 2 patients, epidural hematoma in 1) in this series required surgical intervention. The patient in Case 1 had a permanent chest tube inserted prior to surgery to treat malignant pleural effusion from large cell lung cancer. This patient's bilateral pulmonary edema worsened after IM surgery, which led to reintubation 2 days later and then to tracheostomy. After successful weaning from the ventilator, he was transferred to a subacute nursing facility. The patient in Case 9 developed an epidural wound hematoma 1 week after IM surgery that required emergency evacuation, and she remains paraplegic at follow-up.

\section{Neurological Outcomes}

Twelve patients had Frankel Grade D neurological function before surgery, and 1 had Grade C (Table 3). In 6, neurological function declined to Frankel Grade $\mathrm{C}$ immediately after surgery; in 6, it remained at Grade D (and 2 months later it reached Grade $\mathrm{E}$ in 1 of these). The patient in Case 9 had a postoperative Frankel Grade D, but developed an epidural hematoma 1 week after surgery, leading to paraplegia, and now functions at Frankel Grade A. At 2 months the functional scores in 4 of the 6 patients in whom a decline was seen after surgery had returned to Grade D; 2 patients remained at Grade C.

The remaining patient presented at Frankel Grade C and improved promptly after subtotal surgical decompression to Grade D. She maintained this level for 4 months, until her death from intracranial hypertension.

Of the 9 survivors at 5 months, 7 patients had Frankel Grade D (1 patient's score had deteriorated from Grade E to $\mathrm{D}$ because of local disease recurrence), 1 had Grade $\mathrm{C}$, and 1 had Grade A. At the 6- to 12-month follow-up of the 6 survivors, all but 1 patient had Frankel Grade D.

Distant progression of CNS disease affected the neurological outcome of 2 of the 4 patients in whom LMD was diagnosed radiographically on follow-up. In the patient in Case 6 (with breast cancer), a second intramedullary tumor was diagnosed at C-2 6 months after GTR of IM at T-3. This second tumor was treated with steroids and CyberKnife SRS at another institution; the patient then developed progressive quadriparesis, and ultimately LMD. In the patient in Case 8, complete removal of a breast cancer metastasis was not possible due to indistinct planes between tumor and spinal cord. Despite postoperative irradiation of the tumor remnant, this patient developed LMD 4 months after surgery, with significant intracranial involvement leading to her death soon thereafter. Leptomeningeal disease also occurred after surgery in the patients in Cases 2 and 11, but with intrathecal treatment it did not worsen prior to their deaths from systemic metastasis. In the patient in Case 13 (with renal cell carcinoma) a cerebellar lesion appeared 1 year after IM surgery and was successfully treated with SRS. Four years after IM surgery, he underwent distal pancreatectomy with en bloc splenectomy for pancreatic metastasis. He is currently intact neurologically.

\section{Local Recurrence}

Tumor recurred locally (after GTR) in 3 patients during 
TABLE 3. Intramedullary spinal metastasis: pre- and postoperative Frankel grades measuring neurological function

\begin{tabular}{|c|c|c|c|c|c|c|c|}
\hline \multirow[b]{2}{*}{$\begin{array}{c}\text { Case. } \\
\text { No. }\end{array}$} & \multicolumn{5}{|c|}{ Frankel Grade } & \multirow[b]{2}{*}{ Other CNS Disease } & \multirow[b]{2}{*}{ Comments } \\
\hline & Preop & Postop & $\begin{array}{c}2 \\
\text { Mos } \\
\text { Postop }\end{array}$ & $\begin{array}{c}5 \\
\text { Mos } \\
\text { Postop }\end{array}$ & $\begin{array}{l}\text { 6-12 } \\
\text { Mos } \\
\text { Postop }\end{array}$ & & \\
\hline 1 & D & C & C & NA & NA & $\begin{array}{l}\text { Brain metastasis treated } 3 \text { mos earlier w/ } \\
\text { resection + WBRT; no disease at time of } \\
\text { surgery }\end{array}$ & $\begin{array}{l}\text { Cranial disease did not affect neurological outcome } \\
\text { before death }\end{array}$ \\
\hline 2 & $D$ & C & $D$ & D & D & $\begin{array}{l}\text { Multiple intracerebral metastases s/p WBRT } \\
\text { at time of spine surgery; Ommaya reser- } \\
\text { voir implanted for LMD } 2 \text { mos later }\end{array}$ & $\begin{array}{l}\text { Cranial disease did not affect neurological outcome } \\
\text { before death from progressive systemic disease }\end{array}$ \\
\hline 3 & D & C & D & D & NA & $\begin{array}{l}\text { None at time of surgery; brain metastases } \\
\text { seen on staging MRI } 3 \text { mos after surgery; } \\
\text { these lesions progressed despite WBRT }\end{array}$ & $\begin{array}{l}\text { Cranial disease did not affect neurological outcome } \\
\text { before death }\end{array}$ \\
\hline 4 & $\mathrm{D}$ & C & C & C & NA & $\begin{array}{l}\text { Cerebellar metastasis resected } 6 \text { mos } \\
\text { before spine surgery; no disease at time } \\
\text { of surgery }\end{array}$ & $\begin{array}{l}\text { Cranial disease did not affect neurological outcome; } \\
\text { died of rapidly progressing systemic disease }\end{array}$ \\
\hline 5 & D & D & $E$ & D & NA & None & $\begin{array}{l}\text { Local recurrence } 3.8 \text { mos after surgery; treated w/ } \\
\text { dexamethasone; neurological function declined } 1 \\
\text { level during remaining lifetime }\end{array}$ \\
\hline 6 & D & C & D & D & $\mathrm{D}$ & $\begin{array}{l}1 \text { yr prior had craniotomy + WBRT for } \\
\text { metastasis; SRS for small recurrence at } \\
\text { surgical site } 6 \text { mos prior; no disease at } \\
\text { time of surgery; developed LMD } 14 \text { mos } \\
\text { after surgery }\end{array}$ & $\begin{array}{l}6 \text { mos after spine surgery had separate enhancing } \\
\text { lesion at C-2, treated w/ steroids \& CyberKnife; } \\
\text { despite treatment, lesion grew \& patient devel- } \\
\text { oped progressive quadriparesis }\end{array}$ \\
\hline 7 & D & C & D & NA & NA & $\begin{array}{l}\text { Frontal lobe brain metastasis found at time } \\
\text { of IM, treated w/ SRS }\end{array}$ & $\begin{array}{l}\text { Died } 3 \text { mos later w/ progressive systemic disease \& } \\
\text { severe pain syndrome requiring Versed drip; had } \\
\text { local recurrence at } 2.2 \text { mos }\end{array}$ \\
\hline 8 & C & D & D & NA & NA & $\begin{array}{l}\text { Parietal metastasis found at time of IM, } \\
\text { treated w/ WBRT; diagnosed w/ LMD } \\
\text { shortly before death }\end{array}$ & $\begin{array}{l}\text { Died } 4 \text { mos later after rapid obtundation, suggesting } \\
\text { hydrocephalus \&/or progression of intracranial } \\
\text { tumor (imaging not available) }\end{array}$ \\
\hline 9 & D & D & A & A & $A$ & $\begin{array}{l}\text { Cerebellar metastatic lesion treated w/ } \\
\text { radiation therapy } 2 \text { yrs prior; occipital } \\
\text { lesion treated w/ SRS } 7 \text { mos prior to IM } \\
\text { resection }\end{array}$ & $\begin{array}{l}\text { Cranial disease did not affect neurological outcome, } \\
\text { patient had excellent response to radiation, but } 1 \\
\text { wk after resection an epidural hematoma devel- } \\
\text { oped, requiring emergency evacuation; patient } \\
\text { remains paraplegic } 21 \text { mos later }\end{array}$ \\
\hline 10 & D & D & D & NA & NA & $\begin{array}{l}\text { Skull base resection of radiation-induced } \\
\text { sarcoma } 2 \text { mos prior to IM resection; } \\
\text { nodularity in brain based on preop MRI }\end{array}$ & $\begin{array}{l}\text { Parotid malignancy treated } 20 \text { yrs prior w/ resection } \\
\& \text { radiation; cranial disease did not affect neuro- } \\
\text { logical outcome before death }\end{array}$ \\
\hline 11 & $\mathrm{D}$ & D & D & D & $\mathrm{D}$ & $\begin{array}{l}\text { Developed LMD, which stabilized on intra- } \\
\text { thecal therapy }\end{array}$ & $\begin{array}{l}\text { Repeat surgery } 1 \text { wk after initial resection for CSF } \\
\text { leak repair; died of hepatic failure at } 36 \text { mos }\end{array}$ \\
\hline 12 & $\mathrm{D}$ & D & D & D & D & $\begin{array}{l}\text { Recurrent T-11 lesion } 1 \text { yr after initial IM } \\
\text { resection, treated w/ resection \& radia- } \\
\text { tion; initial IM resection was not followed } \\
\text { by radiation }\end{array}$ & $\begin{array}{l}\text { Remains neurologically intact w/ mild iliopsoas } \\
\text { weakness w/o evidence of CNS recurrence at } 65 \\
\text { mos of follow-up }\end{array}$ \\
\hline 13 & D & $\mathrm{D}$ & D & D & D & $\begin{array}{l}\text { Craniotomy + WBRT for metastatic lesion } 2 \\
\text { yrs prior to IM; no evidence of cranial me- } \\
\text { tastasis at time of IM resection; cerebellar } \\
\text { metastasis found } 1 \text { yr after IM \& treated } \\
\text { w/ SRS }\end{array}$ & $\begin{array}{l}\text { Cranial disease did not affect neurological outcome; } \\
\text { alive \& ambulatory at } 65 \text { mos; underwent } \\
\text { pancreatectomy \& en bloc splenectomy for } \\
\text { metastatic lesions, \& is currently being evaluated } \\
\text { for pancreatic metastasis }\end{array}$ \\
\hline
\end{tabular}

$\mathrm{NA}=$ not applicable.

the follow-up period. The patient in Case 5 (with breast cancer) had local recurrence 15 weeks after surgery. This patient had received fractionated preoperative irradiation. After her neurological condition declined, she was treated with dexamethasone, and her condition remained stable until her death 5 months after surgery. The patient in Case 7 (with renal cell cancer) developed a local recurrence at 9 weeks, which caused severe pain. His systemic disease 
TABLE 4. Intramedullary spinal cord metastasis: treatment, local recurrence, CNS progression, and survival

\begin{tabular}{|c|c|c|c|c|c|c|c|}
\hline $\begin{array}{l}\text { Case } \\
\text { No. }\end{array}$ & $\begin{array}{l}\text { Extent of } \\
\text { Resection }\end{array}$ & XRT Preop & XRT Postop & $\begin{array}{c}\text { Local } \\
\text { Recurrence }\end{array}$ & $\begin{array}{l}\text { CNS Disease Progression } \\
\text { at Other Sites Affecting } \\
\text { Neurological Outcome }\end{array}$ & $\begin{array}{l}\text { LMD Postop } \\
\text { \& Time to } \\
\text { Develop (mos) }\end{array}$ & $\begin{array}{c}\text { Survival } \\
\text { Postop (mos) }\end{array}$ \\
\hline 1 & GTR & No & No & No & No & No & 2.2 \\
\hline 2 & STR & No & Yes; 20 Gy, 5 fractions & No & No & Yes, 2.0 & 7.4 \\
\hline 3 & GTR & No & Yes; 20 Gy, 5 fractions & No & No & No & 5.2 \\
\hline 4 & GTR & No & No & No & No & No & 6.5 \\
\hline 5 & GTR & Yes; 45 Gy, 25 fractions & No & Yes & No & No & 5.0 \\
\hline 6 & GTR & No & No & No & Yes & Yes, 14 & 15.3 \\
\hline 7 & GTR & No & Yes; 30 Gy, 10 fractions & Yes & No & No & 2.9 \\
\hline 8 & STR & No & Yes; 35 Gy, 14 fractions & No & Yes & Yes, 3.8 & 4.0 \\
\hline 9 & GTR & No & Yes; 50.4 Gy, 28 fractions & No & No & No & Alive at $21 \mathrm{mos}$ \\
\hline 10 & STR & No & Yes; 30 Gy, 10 fractions & No & No & No & 3.8 \\
\hline 11 & STR & No & Yes; 37.5 Gy, 15 fractions & No & No & No & 36 \\
\hline 12 & GTR & No & Yes; 35 Gy, 14 fractions* & Yes & No & No & Alive at $65 \mathrm{mos}$ \\
\hline 13 & GTR & No & No & No & No & No & Alive at $65 \mathrm{mos}$ \\
\hline
\end{tabular}

$\mathrm{XRT}=$ radiotherapy.

* Radiotherapy given only after second resection of (recurrent) IM

advanced rapidly, and he died 3 months later. The patient in Case 12 (with renal cell carcinoma) developed a recurrent T-11 lesion 1 year postoperatively, underwent a second resection and radiotherapy, and remains at Frankel Grade $\mathrm{D}$ at 65 months. Thus, the rate of local recurrence at the operative site was $23 \%$, and no patient showed recurrence past 1 year from surgery.

\section{Survival Outcomes}

Survival duration ranged from 2.2 to 36 months from the time of surgery (Table 4), excluding the 3 patients who are currently alive. The mean survival of those currently alive is 50 months. The median survival for the entire cohort was 6.5 months. The 3 patients with breast cancer had a mean survival of 8.1 months. Those with renal cell carcinoma had the best chance for long-term survival; 2 of the 4 patients with renal cancer are currently living, both with 50 months of follow-up. The patient in Case 2 survived more than 7 months after STR of cervical cancer IM followed by external-beam radiation. However, the limited number of patients prohibits a reliable correlation between histological findings and survival or functional outcome.

\section{Discussion}

\section{General Series of IM}

A variety of tumor types have been described as causing IM. $1,2,8,18,20,22,27$ In reviews of previously reported cases of IM, Grem et al., Connolly et al., and Kalayci et al. described 50, 174, and 284 cases, respectively, many of which overlap. $5,13,17$ Lung cancer constituted half of the primary cancers, most of which were the small cell subtype, followed by breast cancer in 13\%-14\% of cases. Grem et al., Connolly et al., and Kalayci et al. all reported a survival benefit in early detection and radiation therapy, but failed to clearly define the role of surgery. Similarly, Schiff and
O'Neill described a case series of 40 patients, although only 5 underwent surgery. ${ }^{27}$ Again, the majority of patients demonstrated small cell lung cancer, probably reflecting a selection bias favoring radiation therapy as primary treatment. ${ }^{17,22}$ A survival benefit was noted with radiation, and the authors concluded that early detection and radiotherapy can help preserve neurological function.

\section{Histological Type-Specific Series of IM}

Several authors have published small histological typespecific series of IM. Potti et al. described 7 cases associated with non-small cell lung cancer treated with chemotherapy and radiation, with a median survival of 10 months. ${ }^{25}$ Another 6 cases of IM (all from renal cell cancer) were reported by Fakih et al. ${ }^{9}$ Renal cell cancer accounts for $4 \%$ of all IM cases. ${ }^{5,13}$ Surgery was performed in 2 patients to stem rapid neurological decline. With the exception of 1 of the surgical cases, all patients received radiotherapy. Neurological function stabilized in all, but did not improve in any patient. Survival was variable, ranging from 4 to 23 months, and the median survival was 10 months. In our own patients with IM, better outcomes occurred in renal cell carcinoma than in other cancer types. Boström et al. reported their 20-year institutional experience comprising 70 intramedullary spine tumors, although nearly threequarters of cases were glioma or ependymoma and only $11 \%$ were metastases. ${ }^{3}$ Of the metastatic cases $(n=8)$, we achieved GTRs in half, and 5 also received adjuvant radiotherapy. Tumor histological findings included lung $(n=5$; all dead within 6 months of surgery); 1 patient with renal cell carcinoma who remained symptom-free at 13 months; 1 case of esthesioneuroblastoma that recurred at 4 months; and no follow-up was available for the remaining patient, who had an unknown primary carcinoma. Of these 8 surgical cases, 1 patient had improvement in neurological status, 1 had a decline, and 6 had no significant change. 
Four cases of IM from advanced breast cancer highlight the poor prognosis of these patients when treated only with steroids and radiotherapy. ${ }^{18}$ Three patients died 2-5 months after diagnosis, and 1 was alive after 6 months. Carcinoma of the breast has an increased rate of LMD, and in $25 \%$ of patients with LMD, direct parenchymal invasion occurs. ${ }^{18,27}$ Nevertheless, our patient (Case 6) with this histological type, who survived more than 15 months after surgery and had good maintenance of neurological function, shows that surgery may provide meaningful palliation for some, particularly for those without LMD or parenchymal invasion.

\section{Surgical Nuances}

Resection for IM has a role in patients who have rapidly declining neurological function, good preoperative KPS score, radioresistant tumor, radiation failure, or systemic disease with known indolent growth pattern, All of our patients fulfilled one or more of these criteria. Surgery was well tolerated, with minimal morbidity and no perioperative deaths, although short-term deterioration in neurological function did typically occur. The relative lack of neurological morbidity in our series, and the long-term survival seen in $30 \%$ of patients, suggests that a surgical approach to maintain function may be warranted in this select group of patients.

Transient deterioration in neurological function was noted postoperatively in 6 of 13 patients, but our experience suggests that neurological recovery usually follows in this situation. Indeed, the only patient who was wheelchair-bound before surgery regained ambulation promptly after tumor resection. The median survival in our patients was long enough to suggest that judicious surgical management should be considered. With such a small number of patients, it is unclear whether surgery for IM affects overall survival, which probably relates more to how well systemic disease is controlled thereafter.

Because of the association of IM with LMD, with its implications for limited life expectancy, clinicians may hesitate to propose surgical treatment. Case reports and small series have demonstrated the successful surgical removal of isolated IM, leading to enhanced quality of life or to long-term survival. $7,10,18,30,34$ Some authors have argued that the presence of LMD prior to surgery has little effect on survival. ${ }^{12}$ To maximize success, we excluded patients with evident LMD from consideration for surgery. Given that lumbar puncture and MRI are imperfect indicators of LMD, with malignant cells identifiable on cytospin in $50 \%-75 \%$ of patients with IM, it is possible that one or more of our patients did, in fact, have LMD prior to surgery. ${ }^{28}$ However, because 9 of the 13 patients did not develop LMD after resection, its specter should not preclude consideration of IM for surgical treatment. This is particularly true given that 2 of our 4 patients with LMD showed good response to intrathecal drug therapy, and did not show neurological decline prior to death.

The natural history of untreated IM includes rapid irreversible neurological decline via the accumulation of IM at other sites, local pressure, cord edema, and cord infarction. ${ }^{13,32,35}$ Steroid therapy and radiotherapy are the standard nonsurgical treatments. In general, radiotherapy is effective when the neurological deficits are minor and the tumor biology implies radiosensitivity. ${ }^{13,27,33,35}$ However, some authors have argued that resection can extend survival. $5,7,17,24,30,34$ Our data cannot support this suggestion without a valid control group treated nonsurgically; but they do show that quality of life may be maintained or improved in some patients after surgery. The pattern of neurological recovery seen in our analysis is similar to that of patients with primary spinal cord tumors treated with surgery. In a study of ependymomas of the spinal cord at our institution, 11 of 26 patients (42\%) had a similar initial decrease in neurological scores, with subsequent improvement. ${ }^{14}$

\section{Surgical Results: Function and Survival}

Four other series focusing on surgery for IM have been published to date., ${ }^{72,24,34}$ The 13 patients described by Gasser et al. had similar survival to that of our group, but significantly worse functional outcome, which was probably reflective of the greater difficulty these authors experienced in achieving GTRs (46\% in their series, $69 \%$ in ours). ${ }^{12}$ Preoperative Frankel grades were similar, but the majority (77\%) of their patients had tumor in the relatively less forgiving thoracic cord or conus, histological findings more commonly involved in sarcoma $(n=3)$, or poorly differentiated carcinoma $(n=3)$. These differences underscore the basic message of our series: that good outcomes can be achieved with microsurgical removal of IM, but that success is influenced by histological type and by the degree of resection.

Wilson et al. published a series of 9 patients with IM undergoing surgery. ${ }^{34}$ The primary histological findings were adenocarcinoma of the breast $(n=4)$ and lung $(n=$ $3)$, and melanoma $(n=2)$. Four $(44 \%)$ patients were ambulatory preoperatively, with a mean KPS score of 60 . Gross-total resection was achieved in 8 of the cases, with no complications. The mean survival after surgery was 6.4 \pm 9.4 months, with 7 patients undergoing adjuvant radiotherapy. Postoperatively, 4 of the patients had no change in motor strength, 2 improved, and 3 deteriorated. In another review of surgery for IM, the majority had lung cancer lesions $(\mathrm{n}=13 ; 68 \%), 6$ of which were small cell carcinoma, with breast cancer in second place $(\mathrm{n}=3 ; 16 \%){ }^{7}$ Neurological status improved in $7(54 \%)$ patients within 1 week, worsened in 4 patients, and 2 patients maintained their preoperative neurological status, leading the authors to conclude that surgery can be of benefit in the setting of rapidly progressive neurological deficits and when a clear cleave plane exists.

The largest surgical series of IM to date comes from Payer et al., who studied 22 patients. ${ }^{24}$ Here again, comparison is difficult because (unlike in our series) lung cancer was the dominant histological type, and one-third of the patients had unknown primary carcinoma. This series also seems to include patients with drop metastases from gliomas, which are not typically classified as intramedullary; and, as in all the surgical series discussed here but ours, the worse functional outcome was skewed by the more severe loss of neurological function at presentation.

None of these series are directly comparable to the surgical series we report here. When surgery was performed 
by the majority of other authors, it was done without consistent selection criteria and generally for the purpose of tumor debulking. By contrast, we excluded patients with up-front LMD and made every effort to achieve as complete a resection as safety allowed. Our outcome data suggest that this strategy resulted in more long-term survivors and excellent maintenance of neurological function after surgery.

\section{Radiotherapy as Primary Treatment}

Radiotherapy as primary treatment for IM is minimally invasive and can halt tumor progression and decline in neurological status; however, its efficacy is limited to radiosensitive tumors. ${ }^{20,22}$ Sung et al. reported their 20-year experience in managing IM and provided a literature review of 293 additional cases. ${ }^{31}$ The median survival values of the surgical and radiotherapeutic management cohorts were 6 months and 5 months, respectively-much better than the 1 month achieved by palliative care only. Neurological status improved in $58 \%$ of surgically treated cases versus $21 \%$ of those treated with radiotherapy alone.

Several reports have described the efficacy of radiosurgery in treating IM. ${ }^{15,23,29}$ Parikh and Heron reported on a patient with IM from renal cell carcinoma who was treated by CyberKnife with 15 Gy in 3 fractions, who was alive and fully functional 26 months later ${ }^{23}$ Shin et al. reported a series of intramedullary lesions undergoing single-fraction radiosurgery with the Novalis system for metastasis from melanoma $(n=1)$, breast $(n=2)$, renal cell carcinoma $(\mathrm{n}=1)$, and non-small cell lung cancer $(\mathrm{n}=1) .{ }^{29}$ The mean treatment dose was 14.4 Gy (range 12-16 Gy). Clinical improvement occurred in 4 of the 5 patients. The median survival was 5.2 months (range 2.2-19.4 months). Hashii et al. reported on 18 patients with IMs that were treated with fractionated radiotherapy, whose primary histological types included cancers of the lung (non-small cell [ $\mathrm{n}=$ $6]$, small cell $[n=2])$, breast $(n=6)$, melanoma $(n=2)$, kidney $(n=1)$, and colon $(n=1) \cdot{ }^{15}$ The median survival was 4 months. Ten patients showed clinical improvement after radiotherapy. Long-term outcome studies of radiotherapy in the management of IM have not been done, and the rarity of such metastases makes it unlikely that controlled prospective clinical studies comparing surgery versus radiotherapy will be possible.

It is important to note that the patients in this surgical series are a highly select group, one quite different from the overall cohort of patients with IM. Unlike the patients in our surgical cohort, many of those treated by other means have LMD, multiple sites of metastasis in the cord, and/or very poor functional status. For this reason, we have refrained from making any comparison between the surgical subset we report here and the much larger group treated in most centers by radiotherapy.

\section{Conclusions}

In most patients, spinal cord function returned soon after the immediate postoperative period, and was preserved for the patients' lifetime. Our data suggest that surgery can be used in a subset of patients with relatively good functional status and progressive neurological deficit (but without evident LMD) to prevent further decline. Cases of IM will be seen more frequently because of early detection and longer survival, and treatment strategies (including the appropriate selection of patients for surgery) will require further definition.

\section{References}

1. Amin R: Intramedullary spinal metastasis from carcinoma of the cervix. Br J Radiol 72:89-91, 1999

2. Ateaque A, Martin JL, O’Brien C: Intramedullary spinal cord metastases from a hypernephroma 11 years following the diagnosis and treatment of the primary lesion. Br $\mathbf{J}$ Neurosurg 14:474-476, 2000

3. Boström A, Kanther NC, Grote A, Boström J: Management and outcome in adult intramedullary spinal cord tumours: a 20-year single institution experience. BMC Res Notes 7:908, 2014

4. Chason JL, Walker FB, Landers JW: Metastatic carcinoma in the central nervous system and dorsal root ganglia. A prospective autopsy study. Cancer 16:781-787, 1963

5. Connolly ES Jr, Winfree CJ, McCormick PC, Cruz M, Stein BM: Intramedullary spinal cord metastasis: report of three cases and review of the literature. Surg Neurol 46:329-338, 1996

6. Costigan DA, Winkelman MD: Intramedullary spinal cord metastasis. A clinicopathological study of 13 cases. J Neurosurg 62:227-233, 1985

7. Dam-Hieu P, Seizeur R, Mineo JF, Metges JP, Meriot P, Simon $\mathrm{H}$ : Retrospective study of 19 patients with intramedullary spinal cord metastasis. Clin Neurol Neurosurg 111:10-17, 2009

8. Ding DC, Chu TY: Brain and intramedullary spinal cord metastasis from squamous cell cervical carcinoma. Taiwan $\mathbf{J}$ Obstet Gynecol 49:525-527, 2010

9. Fakih M, Schiff D, Erlich R, Logan TF: Intramedullary spinal cord metastasis (ISCM) in renal cell carcinoma: a series of six cases. Ann Oncol 12:1173-1177, 2001

10. Findlay JM, Bernstein M, Vanderlinden RG, Resch L: Microsurgical resection of solitary intramedullary spinal cord metastases. Neurosurgery 21:911-915, 1987

11. Frankel HL, Hancock DO, Hyslop G, Melzak J, Michaelis LS, Ungar GH, et al: The value of postural reduction in the initial management of closed injuries of the spine with paraplegia and tetraplegia. I. Paraplegia 7:179-192, 1969

12. Gasser T, Sandalcioglu IE, El Hamalawi B, van de Nes JA, Stolke D, Wiedemayer H: Surgical treatment of intramedullary spinal cord metastases of systemic cancer: functional outcome and prognosis. J Neurooncol 73:163-168, 2005

13. Grem JL, Burgess J, Trump DL: Clinical features and natural history of intramedullary spinal cord metastasis. Cancer 56:2305-2314, 1985

14. Hanbali F, Fourney DR, Marmor E, Suki D, Rhines LD, Weinberg JS, et al: Spinal cord ependymoma: radical surgical resection and outcome. Neurosurgery 51:1162-1174, 2002

15. Hashii H, Mizumoto M, Kanemoto A, Harada H, Asakura $\mathrm{H}$, Hashimoto T, et al: Radiotherapy for patients with symptomatic intramedullary spinal cord metastasis. J Radiat Res (Tokyo) 52:641-645, 2011

16. Hashizume Y, Hirano A: Intramedullary spinal cord metastasis. Pathologic findings in five autopsy cases. Acta Neuropathol 61:214-218, 1983

17. Kalayci M, Cağavi F, Gül S, Yenidünya S, Açikgöz B: Intramedullary spinal cord metastases: diagnosis and treatmentan illustrated review. Acta Neurochir (Wien) 146:13471354,2004

18. Kosmas C, Koumpou M, Nikolaou M, Katselis J, Soukouli G, Markoutsaki N, et al: Intramedullary spinal cord metastases in breast cancer: report of four cases and review of the literature. J Neurooncol 71:67-72, 2005 
19. Lee SS, Ahn JH, Kim MK, Sym SJ, Gong G, Ahn SD, et al: Brain metastases in breast cancer: prognostic factors and management. Breast Cancer Res Treat 111:523-530, 2008

20. Lyding JM, Tseng A, Newman A, Collins S, Shea W: Intramedullary spinal cord metastasis in Hodgkin's disease. Rapid diagnosis and treatment resulting in neurologic recovery. Cancer 60:1741-1744, 1987

21. Mostardi PM, Diehn FE, Rykken JB, Eckel LJ, Schwartz KM, Kaufmann TJ, et al: Intramedullary spinal cord metastases: visibility on PET and correlation with MRI features. AJNR Am J Neuroradiol 35:196-201, 2014

22. Murphy KC, Feld R, Evans WK, Shepherd FA, Perrin R, Sima AA, et al: Intramedullary spinal cord metastases from small cell carcinoma of the lung. J Clin Oncol 1:99-106, 1983

23. Parikh S, Heron DE: Fractionated radiosurgical management of intramedullary spinal cord metastasis: A case report and review of the literature. Clin Neurol Neurosurg 111:858861, 2009

24. Payer S, Mende KC, Westphal M, Eicker SO: Intramedullary spinal cord metastases: an increasingly common diagnosis. Neurosurg Focus 39(2):E15, 2015

25. Potti A, Abdel-Raheem M, Levitt R, Schell DA, Mehdi SA: Intramedullary spinal cord metastases (ISCM) and non-small cell lung carcinoma (NSCLC): clinical patterns, diagnosis and therapeutic considerations. Lung Cancer 31:319-323, 2001

26. Rykken JB, Diehn FE, Hunt CH, Schwartz KM, Eckel LJ, Wood CP, et al: Intramedullary spinal cord metastases: MRI and relevant clinical features from a 13-year institutional case series. AJNR Am J Neuroradiol 34:2043-2049, 2013

27. Schiff D, O'Neill BP: Intramedullary spinal cord metastases: clinical features and treatment outcome. Neurology 47:906912, 1996

28. Schuknecht B, Huber P, Büller B, Nadjmi M: Spinal leptomeningeal neoplastic disease. Evaluation by MR, myelography and CT myelography. Eur Neurol 32:11-16, 1992

29. Shin DA, Huh R, Chung SS, Rock J, Ryu S: Stereotactic spine radiosurgery for intradural and intramedullary metastasis. Neurosurg Focus 27(6):E10, 2009

30. Stranjalis G, Torrens MJ: Successful removal of intramedul- lary spinal cord metastasis: case report. Br J Neurosurg 7:193-195, 1993

31. Sung WS, Sung MJ, Chan JH, Manion B, Song J, Dubey A, et al: Intramedullary spinal cord metastases: a 20 -year institutional experience with a comprehensive literature review. World Neurosurg 79:576-584, 2013

32. Tognetti F, Lanzino G, Calbucci F: Metastases of the spinal cord from remote neoplasms. Study of five cases. Surg Neurol 30:220-227, 1988

33. Vindlacheruvu RR, McEvoy AW, Kitchen ND: Intramedullary thoracic cord metastasis managed effectively without surgery. Clin Oncol (R Coll Radiol) 9:343-345, 1997

34. Wilson DA, Fusco DJ, Uschold TD, Spetzler RF, Chang SW: Survival and functional outcome after surgical resection of intramedullary spinal cord metastases. World Neurosurg 77:370-374, 2012

35. Winkelman MD, Adelstein DJ, Karlins NL: Intramedullary spinal cord metastasis. Diagnostic and therapeutic considerations. Arch Neurol 44:526-531, 1987

\section{Disclosures}

Dr. Rhines is a consultant for Stryker and Globus.

\section{Author Contributions}

Conception and design: all authors. Acquisition of data: Strickland, McCutcheon, Chakrabarti, Rhines. Analysis and interpretation of data: all authors. Drafting the article: Strickland, McCutcheon, Rhines, Weinberg. Critically revising the article: all authors. Reviewed submitted version of manuscript: all authors. Approved the final version of the manuscript on behalf of all authors: Strickland. Statistical analysis: Strickland. Administrative/technical/material support: Weinberg. Study supervision: McCutcheon, Weinberg.

\section{Correspondence}

Ben A. Strickland, The Keck School of Medicine of the University of Southern California, Los Angeles, 1200 N State St., Ste. 3300, Los Angeles, CA 90033. email: ben.strickland@med. usc.edu. 